\title{
Stability Analysis of Cracks in Concrete Lining Structure of Water Conveyance Tunnel \\ Yongjin $\mathrm{Wu}^{1, a}$, Shuling Huang ${ }^{1, b}$, Huizi Shi ${ }^{2, c}$
}

\author{
${ }^{1}$ Key Laboratory of Geotechnical Mechanics and Engineering of Ministry of Water Resources, \\ Changjiang River Scientific Research Institute, Wuhan 430010, China \\ ${ }^{2}$ Hubei Water Resources Research Institute, Wuhan 430070, China \\ awuyj@hhu.edu.cn, b149126797@qq.com, chz.shi@foxmail.com
}

\begin{abstract}
Keywords: cracks; water conveyance tunnel engineering; concrete lining; compression shear crack; stress intensity factor

Abstract. Lining crack is a primary disease in water conveyance tunnel engineering, and accurate analysis of the stability of lining structure with cracks is critical. Based on the theory of fracture mechanics, the contact model has been used to simulate the contact friction effect of crack surfaces. Combined with the fracture criterion of concrete, the safety evaluation methods for tunnel lining structure with cracks has been established. Taking a water conveyance tunnel for water diversion project as an example, the paper analyzes the influences of crack position and crack angles on the safety of lining structure based on calculating models, and the influences the stability of the tunnel lining with cracks.
\end{abstract}

\section{Introduction}

Long distance water conveyance tunnels mostly cross the western mountain area where the geological structure is complicated. The tunnels are not only deep and high in crustal stress, but also passed through many geological units, the condition of surrounding rock is complicated, and the fracture structure develops, and the surrounding rock-lining structure will bear greater external water pressure which leads to risks of long-term stability in the course of tunnel operation. Among them, the tunnel lining cracks are the main factors affecting the operation of the tunnel, but also the focus of the study. The study of cracks in tunnel lining is mainly focused on the cause of formation and theoretical calculation of cracks. Such as Rong Yao etc, established the calculation method of the crack spacing and width of the tunnel lining which is based on the elastic foundation beam method, Ji Qianqian and so on add the spring element in the crack position to establish the mechanical model of the shield tunnel lining with the crack, Dai Chengyuan and so on analyzed the tunnel concrete lining crack cause of formation and the expansion rule. However, there are few types of research on the influence and evaluation methods of cracks on the safety of tunnel lining structures ${ }^{[1,2]}$. The study of cracks in tunnel lining is a typical discontinuous mechanical problem, in this paper, based on the theory of fracture mechanics, the contact model is used to simulate the contact friction of fracture surface, and the mechanical model of tunnel lining containing cracks is established, taking a water conveyance tunnel for water diversion project as an example, the typical parts are analyzed and calculated, and the influence of the cracks on the stability of the tunnel lining is analyzed.

\section{Characteristics of Lining Concrete Cracks}

The load on the lining structure of long distance water conveyance tunnel is mainly the deformation pressure of surrounding rock and the external water pressure ${ }^{[3]}$. The lining as a safe storage structure of tunnel, is usually applied after the deformation of surrounding rock is stable, but its bearing mechanism and function should be determined according to the differences of surrounding rock, On-site construction, and external water load. When the lithology is better, the smaller the lining bears pressure of surrounding rock, thus mainly to prevent the effects caused by corrosion of steel lining, the range of surrounding rock relaxation extending, the scope of the initial support system instability and 
other factors, to improve the safety of tunnel support structure; When the lithology is poor, the lining can bear larger deformation pressure of surrounding rock in the later stage, and also plays a role in structural waterproofing.

Concrete is a kind of quasi-brittle material with low tensile properties. It is inevitable to produce micro-cracks during the construction and operation of tunnel lining. Such as dry shrinkage cracks, temperature cracks, deformation cracks caused by external force, and other cracks resulting from improper construction and concrete creep. Micro-cracks continue to develop into macro cracks or even unstable cracks under internal causes and external loads, thus controlling the fracture of structures. Lining concrete crack from the view of the distribution location can be divided into Inner surface cracks, outer surface cracks, and internal cracks, and from the crack distribution form, can be divided into a circumferential crack, longitudinal crack, and cross cracks.

Lining cracks are one of the famous disasters that affect the long-term stability and safety of the tunnel, and the occurrence of cracks will reduce the stiffness of the lining, reduce its bearing capacity, accelerate the deterioration of concrete materials and corrosion of the internal steel bars, affect the anti-seepage performance of the rock-lining support system , and eventually lead to the failure of the tunnel rock-lining support system due to the insufficient bearing capacity of the lining. Therefore, effective measures must be taken to reduce and control the crack initiation and instability to improve the stability of the structure ${ }^{[4]}$.

\section{Stability analysis method of tunnel lining cracks}

Analysis of concrete lining crack stability of the long distance water diversion tunnel, stability calculation of crack from the principle and method of fracture mechanics, is the analysis judgment whether crack instability expansion occurs, the main content involves two aspects should be the calculation of stress intensity factors and fracture criterion.

Calculate the stress intensity factor of the lining cracks. The calculation methods of stress intensity factors include an analytical method, numerical method, and experimental method. The analysis method usually needs lots of simplification, and has a higher requirement to the structure shape, and the crack distribution, so numerical method is generally used in general engineering analysis ${ }^{[5]}$. The numerical method for solving the stress intensity factor can be roughly divided into two types: the direct method and the indirect method: the direct method refers to the calculation of stress and displacement of the output value of the solution; The indirect method is obtained by some middle, such as the strain energy release rate $G$ and $J$ integral, etc.

It is necessary to use a very fine mesh to solve the crack problem based on conventional numerical method so that the stress intensity factor can reach a certain level of accuracy. To improve the calculation accuracy and reduce the calculation scale, the singular value method of crack tip is used to solve the value $K^{[6]}$. Henshell and Barsoum found that the normal midpoint of eight nodes and two isoparametric elements moved to the same location of the two sides of the same angle node to the position of the $1 / 4$ side length so that the stress and strain of the unit appeared the singularity $1 / \sqrt{r}$. Based on this, the quadrilateral element for an edge crack in a compressed into a sharp point, and the two sides of the crack tip node to move to the $1 / 4$ side position along the crack tip from any ray of stress, strain $1 / \sqrt{r}$ is singular and is compatible with the non-singular the issues surrounding yuan. When a singular element is used to solve the stress intensity factor, the stress intensity factor is usually obtained from the displacement at $1 / 4$ nodes.

Using the numerical method to obtain the stress intensity factor of the fracture, the composite stress intensity factor $K^{*}$ and the composite state angle $\theta$ are used to reflect the working behavior of I-II compound type cracks comprehensively, its expression is

$$
K^{*}=\sqrt{K_{1}^{2}+K_{\| 1}^{2}} .
$$




$$
\theta=\arctan \frac{K_{\mathrm{Il}}}{K_{1}}
$$

Fracture criterion of lining cracks. $K^{*}$ and $\theta$ only reflects the crack behavior. To determine the stability of crack tips, the fracture criteria must be used. In the complex fracture problem, the expression of $K$ criterion is:

$$
K^{*}=K_{\mathrm{C}}^{*} .
$$

In Eq.3, $K_{C}^{*}$ is the critical value of $K^{*}$. If $K^{*}$ smaller than $K_{C}^{*}$, the crack is stable; if s $K^{*}$ larger than $K_{C}^{*}$, the crack will be unstable expansion; if $K^{*}$ equal to $K_{C}^{*}$, the crack is in a critical state.

The concrete compressive shear fracture is different from the tensile shear fracture, that need to consider material related to the compression and shear performance, closed fracture surface friction properties and material friction properties, in order to obtain the criterion of a practical situation ${ }^{[7-8]}$. Because of the complicated fracture mechanism, the pressure shear fracture problem has not been accepted as a criterion for fracture. The fracture criterion used here through field test week group of concrete, the fatigue crack rock unilateral of compression shear ${ }^{[9]}$ :

$$
\lambda K_{\mathrm{I}}+\left|K_{\mathrm{II}}\right|=\overline{K_{\mathrm{IIC}}} .
$$

$\overline{K_{\mathrm{IIC}}}$ is the shear fracture toughness in a compression state, and can be determined by experiment; $\lambda$ is the shear coefficient, and it can be obtained by the following formula:

$$
\lambda=\overline{K_{\mathrm{IIC}}} / K_{\mathrm{IC}} .
$$

\section{Engineering Applications}

Calculation model. The depth of the tunnel is $600 \mathrm{~m}$, and lithology is sandy slate. The tunnel surrounding rock type is class III. The lining diameter is 4.2 meters, and the outer diameter is $4.8 \mathrm{~m}$, the thickness is $0.6 \mathrm{~m}$. The lining concrete type is C30. In order to avoid the influence of the boundary effect, the range of model $\mathrm{X}$ and $\mathrm{Y}$ is $100 \mathrm{~m}$. Lining cracks are considered for seamless joints without width. The lining crack is considered as crack without width ${ }^{[10]}$. The stability of lining cracks under three kinds of fractures is analyzed, including (1) lining inside longitudinal cracks; (2) lining the inner ring cracks; (3) lining outside longitudinal cracks. The initial length of the crack is taken as $0.2 \mathrm{~m}$, the angle between the crack surface and the radial direction is $0^{\circ}, 30^{\circ}$ and $60^{\circ}$. The tunnel model is shown in Fig.1.

The initial stress field is considered as a uniform stress field $\left(\sigma_{x x}=-15.83 \mathrm{MPa}, \sigma_{y y}=-16.92 \mathrm{MPa}, \tau_{x y}=\right.$ $1.20 \mathrm{MPa})$. The constitutive model of rock mass is an ideal elastic-plastic model with yield-dependent Mohr-Coulomb strength criterion as yield function, and the constitutive model of concrete is a linear elastic model. All mechanical parameters of the materials are shown in Table 1.

Table 1 Mechanical parameters of materials

\begin{tabular}{cccccccc}
\hline & $\begin{array}{c}\text { Elastic } \\
\text { Modulus } \\
{[\mathrm{GPa}]}\end{array}$ & $\begin{array}{c}\text { Poisson's } \\
\text { ratio }\end{array}$ & $\begin{array}{c}\text { density } \\
{\left[\mathrm{g} / \mathrm{m}^{3}\right]}\end{array}$ & $\begin{array}{c}\text { Cohesion } \\
{[\mathrm{MPa}]}\end{array}$ & $\begin{array}{c}\text { Friction } \\
\text { angle }\left[{ }^{\circ}\right]\end{array}$ & $\begin{array}{c}\text { Tensile } \\
\text { strength } \\
{[\mathrm{MPa}]}\end{array}$ & $\begin{array}{c}\text { Compressive } \\
\text { strength } \\
{[\mathrm{MPa}]}\end{array}$ \\
\hline Rock & 8.0 & 0.28 & 2.75 & 0.9 & 42.0 & 0.8 & 40.0 \\
Concrete & 30.0 & 0.20 & 2.40 & - & - & 2.8 & 28.0 \\
\hline
\end{tabular}




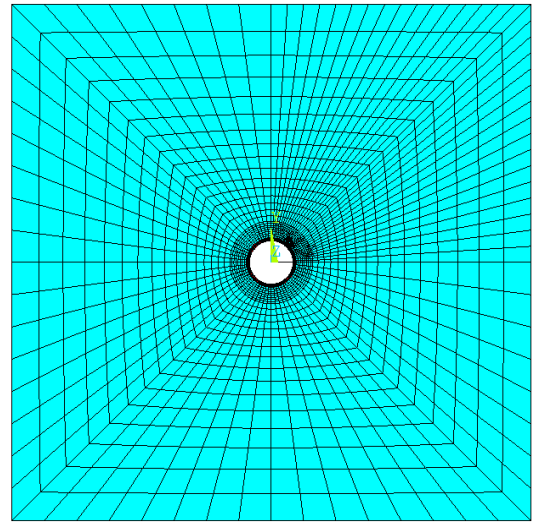

a. Tunnel model

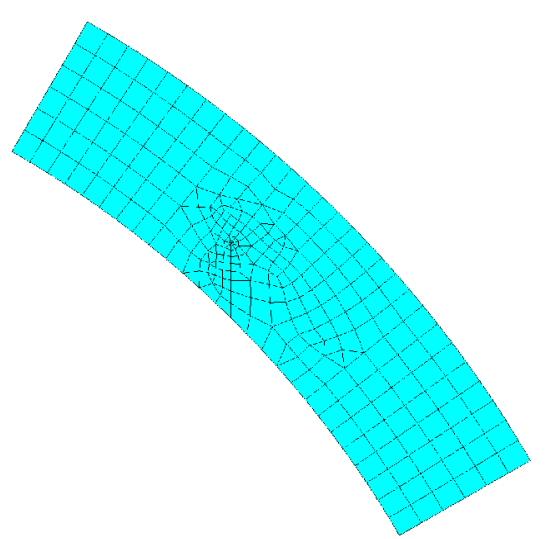

b. Crack distribution diagram

Fig.1. Numerical Simulation Model of Tunnel

Calculation results. The distribution of principal stress after tunnel excavation is given in Fig.2. After the excavation, the surrounding rock is in the state of compression. The stress concentration zone is located at the left arch and the right arch foot. Due to excavation unloading, shallow rock mass appears plastic yield zone. The compressive stress concentration area has been pushed deep into the rock mass, and space $4 \sim 5 \mathrm{~m}$ from the cave surface. The maximum principal compressive stress is about $30 \mathrm{MPa}$. The shallow rock mass has observable stress relaxation phenomenon.

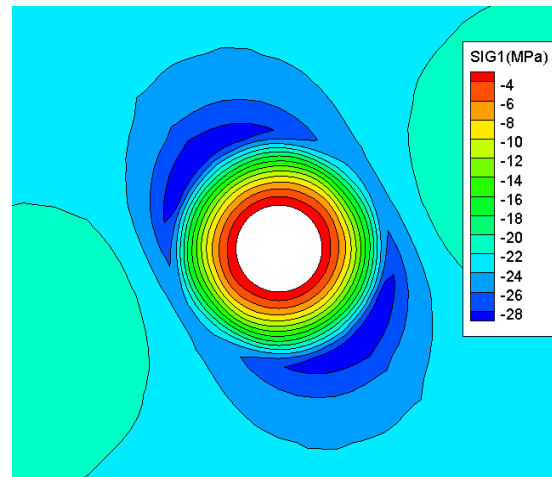

a. Maximum principal stress

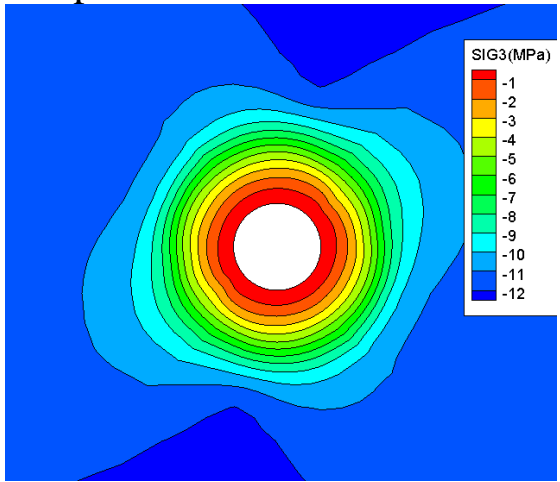

b. Minimum principal stress

Fig.2. The distribution of principal stress after tunnel excavation

Displacement interpolation method is used to calculate the stress intensity factor of the crack tip of concrete lining, the results of the stress intensity factor calculation for different fracture distributions are given in Table 2.

Table 2 Stress Intensity Factor in Different Fracture Distribution

\begin{tabular}{lcccc}
\hline \multicolumn{1}{c}{ Crack type } & $\begin{array}{c}\text { Crack length } \\
{[\mathrm{m}]}\end{array}$ & Crack angle $\left[{ }^{\circ}\right]$ & $\begin{array}{c}K_{\mathrm{I}} \\
{\left[\mathrm{MPa} \cdot \mathrm{m}^{1 / 2}\right]}\end{array}$ & $K_{\mathrm{II}}\left[\mathrm{MPa}^{1 / 2}\right]$ \\
\hline \multirow{2}{*}{ (1) Lining inside longitudinal } & 0.2 & 0 & -1.08 & 0.08 \\
racks & 0.2 & 30 & -0.84 & 0.35 \\
& 0.2 & 60 & -0.49 & 0.46 \\
\hline \multirow{2}{*}{ (2) Lining the inner ring cracks } & 0.2 & 0 & -0.51 & 0.36 \\
& 0.2 & 30 & -0.44 & 0.30 \\
\hline \multirow{2}{*}{ (3) Lining outside longitudinal } & 0.2 & 60 & -0.35 & 0.25 \\
cracks & 0.2 & 0 & -0.87 & 0.12 \\
& 0.2 & 30 & -0.72 & 0.43 \\
\hline
\end{tabular}

According to the fracture performance parameters of the concrete materials obtained in the 
literature $^{[6]}$, the fracture toughness values are as follows:

$$
K_{\mathrm{IC}}=0.7538 \mathrm{MPa} \cdot \mathrm{m}^{1 / 2}, \quad K_{\mathrm{IIC}}=0.5396 \mathrm{MPa} \cdot \mathrm{m}^{1 / 2} \text {. }
$$

Substituting Eq.4 Eq.5, we can obtain the fracture criterion of composite fracture with compression and shear:

$$
0.71 K_{\mathrm{I}}+\left|K_{\mathrm{II}}\right|=0.54 \text {. }
$$

Thus, the stability factor $\mathrm{n}$ can be introduced to characterize the stability of the crack, its expression is:

$$
n=\frac{0.54-0.71 K_{\mathrm{I}}}{\left|K_{\mathrm{II}}\right|}
$$

Obviously, if $n$ is less than 1, the crack will be unstable. According to Eq.8, the values of $n$ under different crack distributions are shown in Fig.3. It can be seen that the $K_{\mathrm{I}}$ values of all types of cracks are less than zero, which are typical compressive shear cracks. The values of $n$ under each scheme are greater than 1, and it can be considered that the crack is stable under the current loading condition. Specifically, for the internal longitudinal cracks of the lining, the shear stress on the crack surfaces increases with the increase of angle between the crack surface and the radial direction while the normal stress decreases. Crack stability is poor and cracks are easier to expand. The longitudinal cracks in the outer lining have the same distribution law, but because of the larger value of external water pressure, the overall stability is worse. For Circumferential cracks in the lining, the $n$ value of the change is smaller.

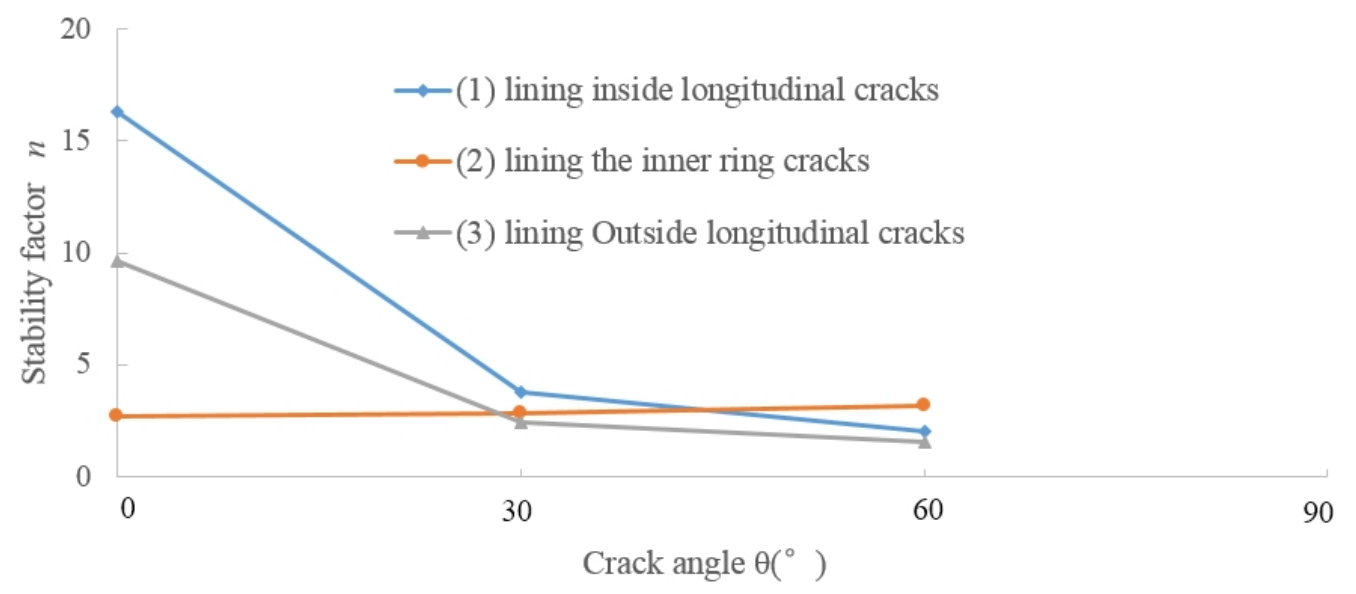

Fig.3. Curve of the relationship between the safety factor $n$ and the crack angle $\theta$

\section{Conclusions}

The stability of cracks in a deep-buried water tunnel is analyzed by using fracture mechanics theory. The results show that the lining structure is basically in the state of compressive stress under the action of surrounding rock pressure and external water pressure. And the lining crack is characterized by a typical compression shear crack. The calculated results also show the crack angle is an important parameter to determine friction contact states of crack surfaces and also an important factor in deciding expansion of cracks and stability of lining structure. The shear stress on the crack surfaces increases and the normal stress decreases with the increase of angle, the stability of the crack is worse.

\section{Acknowledgements}

Financial support from the National Natural Science Foundation of China (Nos. 51539002, Nos. 51379022), the National Key Research and Development Program of China (Nos. 2016YFC0401802, 
2016YFC0401803, 2016YFC0401804), and the Basic Research Fund for the Central Research Institutes of Public Causes (No. CKSF2017054/YT) are greatly acknowledged.

\section{References}

[1] Y.Q. Wei, S.B. Du: Construction features of a super long water conveyance tunnel project with large cross section in construction. Water Resources and Hydropower Engineering Vol. 37 (2006), p. 8

[2] Y.J. Zhang, Z.G. Li: 2D finite element analysis of bearing capacity of tunnel lining with cracks. Rock and Soil Mechanics Vol. 26 (2005), p. 1201

[3] Z.Q. Liu, Q. Zhang: Damage Evolution Analysis OF Permeable Lining of Deep Diversion Tunnel Based on Seepage-Stress Coupling Theory. Chinese Journal of Rock Mechanics and Engineering Vol. 31(2012), p. 2147

[4] S.M. Wang: Analysis and preventive measures of lining concrete cracks in underground chambers. West-china Exploration Engineering Vol. 22(2010), p. 209

[5] X.Z. Yu: Rock and concrete fracture mechanics (Central South University of Technology Press, Changsha 1991)

[6] A.M. Deng: Study on Fracture Criterion Series of Concrete Considering the Influence of Fracture Process Zone. (Hohai University Press, Nanjing 2007)

[7] D.Y. Xu, Z.P. Liang and D.J. Wang: Discussion on fracture criterion of mode I and II composite cracks in concrete. Journal of Hydraulic Engineering Vol. 6 (1982), p. 59

[8] G.Q. Fu: Discussion on fracture model of concrete under compression shear. Journal of Nanchang Institute of Technology Vol. 1 (1987), p. 39

[9] Q.L. Zhou: Compress shear fracture criterion of rock and its application. Chinese Journal of Geotechnical Engineering Vol. 9(1987), p. 33

[10] C.Q. Zhang, X.T. Feng and H. Zhou: Study of some problems about application of stress release method to tunnel excavation simulation. Rock and Soil Mechanics Vol. 29(2008), p. 1174 